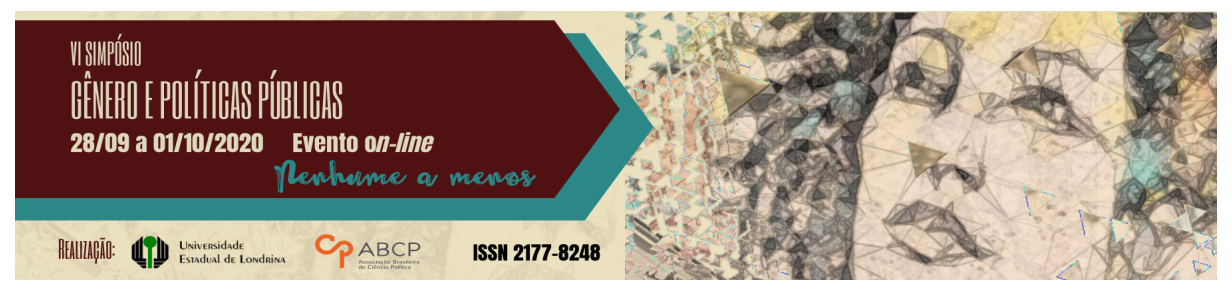

\title{
"Estar aqui, estar lá": novas configurações familiares e afetivas na migração de brasileiros para Europa ${ }^{1}$
}

\author{
Gláucia de Oliveira Assis²
}

\section{Resumo}

O movimento de homens e mulheres brasileiros rumo ao exterior tem se intensificado, novamente, na segunda década do século XXI tem se intensificado colocando novas questões e problemas para aqueles que vivenciam a experiência de conviver entre dois lugares - o Brasil e os vários locais de destino dos emigrantes brasileiros. Nesse cenário dispersado por vários países, como Portugal, Espanha, Inglaterra e Irlanda se consolidam como rotas de mobilidade de brasileiros que buscam "tentar a vida" na Europa. Este trabalho pretende analisar o ir e vir de emigrantes brasileiros entre o Brasil e a Europa, configurando campo de relações transnacionais. A partir de uma pesquisa etnográfica que envolve observação participante e histórias de vida de migrantes, busco compreender os processos de transnacionalização das famílias vivenciados por mulheres e homens emigrantes. O direcionamento do fluxo de brasileiros para a Europa, principalmente a partir dos anos 2000, em função das dificuldades de entrada nos Estados Unidos e da crise econômica que se inicia nos EUA intensifica as idas para Portugal o que nos coloca a questão de compreender os processos de reunificação familiar, os novos arranjos familiares, as reconfigurações nas

\footnotetext{
${ }^{1}$ Este artigo apresenta os resultados iniciais do estágio pós-doutoral desenvolvido no ISCTE - IUL Portugal no período de fevereiro a Julho de 2017. Agradeço ao apoio recebido pelo GOVDIV no período de permanência no ISCTE. Uma primeira versão deste artigo foi apresentada inicialmente no Congresso Latin American Studies Association, sob o título "Trânsitos contemporâneos: gênero, família e afetos nas trajetórias de emigrantes brasileiros na Europa" agradeço aos comentários de Ana Cristina Braga Martes, Maxime Margolis e aos colegas do Painel realizado onde foram discutidos os textos.Artgio apresentado no simpósio de Historia Tempo Presente 2017 1 Artigo vinculado ao projeto de pesquisa "Brasil em notícias, narrativas sobre familias e infância" 'Projeto Fapesc chamada pública Fapesc no 01/2016 - apoio à infraestrutura para grupos de pesquisa da Udesc. Agradecemos a FAPESC o apoio financeiro a realização da pesquisa.

2 Universidade do Estado de Santa Catarina UDESC . Observatório das Migrações de Santa Catarina Programa de pós-graduação em História Programa de pós-graduação em Planejamento Territorial e Desenvolvimento sócio ambiental PPGPLAN.
}

GT 12 - Gênero, refúgio e migrações 
relações de gênero e nos afetos que impactam na vida dos migrantes nesses trânsitos contemporâneos.

Palavras-chave: emigrantes-brasileiros; Brasil-Portugal; gênero; família; afetos.

\section{Introdução}

O Brasil construiu ao longo do século 20, uma autoimagem de um país de imigrantes devido às levas de imigrantes que chegaram do final do século XIX até meados dos anos de 1930. Após esse período, ocorreu uma diminuição das imigrações internacionais devido a politicas migratórias que não privilegiavam mais a migração internacional. Na década de 1960 os brasileiros iniciaram um fluxo esporádico rumo aos Estados Unidos como trabalhadores temporários direcionando para a região da Nova Inglaterra.

Nas décadas de 1960-70 muitos brasileiros emigraram para o exterior. Alguns forçosamente tornando-se exilados políticos da ditadura militar ${ }^{3}$; outros como trabalhadores imigrantes temporários nos Estados Unidos. Embora diferente do exilado político, que vive a condição de "expatriado sem lugar" (Costa et all,1990) e não podia retornar quando desejasse ao país, havia, em ambos os casos, a perspectiva da volta. Neste contexto, estas migrações poderiam ser classificadas como temporárias (Assis, 1999). Esta característica temporária da emigração, bem como a pequena relevância numérica deste fluxo, inicialmente não chamou a atenção nem das autoridades brasileiras nem de estudos acadêmicos, pois o Brasil não possuía tradição emigratória. A emigração de brasileiros tornou-se uma questão relevante, quando o que era um movimento esporádico para o exterior transformou-se num fluxo migratório.

Esse novo movimento de população brasileira tem sido objeto de vários estudos4, desde meados da década de 1990, que procuram compreender características da população migrante, percursos

\footnotetext{
3 Para uma reflexão sobre as experiências de exílio como processos de deslocamento ver Rosalen (2015).

4 Margolis, (1994), Sales (1999), Martes, (2000), Machado (2007), Cavalcanti (2007), Assis (1999, 2004), Siqueira (2009).
} 
migratórios, configuração de redes sociais, a questão da identidade, dentre outras questões que revelam, não apenas a importância do tema, mas o impacto da migração internacional na vida cotidiana das cidades de onde partem um número significativo de migrantes.

Na virada dos anos 2000, consolida-se o ir e vir entre os Estados Unidos e algumas cidades brasileiras e ampliaram-se os locais de destinos dos brasileiros. Vários homens e mulheres se dispersaram pelo mundo em busca de melhores condições de vida, de oportunidades como revelam seus relatos, configurando um novo movimento na população brasileira. Conforme demonstram os estudos de Margolis (1994), Assis (1999) Sales (1999), Martes (2000) Patarra (2005), Bógus e Bassanezi (2008), Martine (2005) esse movimento ocorreu num contexto de crise econômica e política no Brasil que levaram os brasileiros, de camadas médias urbanas, a buscarem oportunidades de mobilidade fora do país. Tais movimentos populacionais inseriram o Brasil na globalização fornecendo trabalhadores/as para o mercado de trabalho secundário (Sales, 1999b).

Dessa forma, cidades no Brasil, iniciaram um processo que conectou processos locais com contextos globais, através do processo de migração internacional. Com a melhoria dos transportes e das comunicações, o barateamento das viagens e a maior circulação de informações, a migração internacional torna-se uma alternativa para camadas médias da população, e também para grupos populares, conforme as informações e redes sociais vão se consolidando em algumas localidades no país, que vem nesse processo uma possibilidade de mobilidade social, de escapar da pobreza, de em alguns contextos, romper padrões familiares e de gênero, ou de viver novas experiências.

Assim como outros imigrantes internacionais, os brasileiros e brasileiras partem com o sonho de trabalhar, juntar dinheiro, fazer investimentos e, em algum momento, retornar para o Brasil, num projeto migratório que podemos chamar de econômico, familiar e 
afetivo (Assis,1995) pois envolve os que partem e os que ficam no projeto. Os emigrantes brasileiros, ao se inserirem no fluxo internacional de mão-de-obra, passam a fazer parte de um mercado que integra áreas remotas em circuitos de mobilidade de longa distância. Segundo Castles (2005), a integração global cria pressões econômicas, políticas, culturais e sociais que convergem no sentido de reforço das migrações a despeito da maior vigilância de controle das fronteiras, tanto nos Estados Unidos quanto na Europa. As migrações tendem a se intensificar, pois são sustentadas por redes sociais que, à medida que os migrantes se instalam e formam comunidades, tendem a "puxar" outros migrantes e a colocar novas práticas e vivências culturais para as sociedades de emigração. Essas redes de migrantes tornam-se a base para a formação de comunidades transnacionais, cujos membros têm parte de existência social vivenciada simultaneamente em mais de um país, como é o caso de algumas cidades no Brasil que construíram conexões entre as localidades de origem e os pontos no destino.

Esse artigo pretende compreender o espraiamento da migração de brasileiros rumo a Europa, principalmente a partir da virada dos anos 2000. Procura ainda analisar como nesse ir e vir gênero e afetos são vivenciados e negociados por mulheres migrantes. Os dados serão apresentados a partir de pesquisa de campo realizada em Lisboa, Londres e cidades na Itália que receberam significativo número de imigrantes brasileiros, destacando-se nesse movimento o incremento do número de mulheres migrantes que, como veremos, tem que negociar com imagens sexualizadas e exotizadas sobre a "mulher brasileira" e se inserem em relações afetivas com europeus.

Esse espraiamento da migração está relacionado para a Europa, por um lado, às dificuldades de obtenção de vistos para os Estados Unidos após os atentados de 11 de setembro de 2001, e por outro à crise financeira que se inicia naquele país em 2008, o que levou muitos emigrantes a considerarem os países da Europa como destino. Por outro lado, há uma intensificação de outras estratégias de mobilidades, como o caso dos estudantes e dos descendentes de imigrantes que 
chegaram ao Brasil no final do século XIX e cuja $3^{\mathrm{a}}$ ou $4^{\mathrm{a}}$ geração consegue com a cidadania trabalhar legalmente na Europa. É o caso de descendentes de imigrantes italianos e alemães (Savoldi, 1999). Uma outra característica desse fluxo, em relação a Europa, é a intensificação da presença das mulheres brasileiras que vivenciam um processo de racialização e exotização como veremos a seguir.

\section{A intensificação dos fluxos de brasileiros rumo a Europa nos anos 2000: Portugal, Inglaterra e Itália}

A emigração de brasileiros para Portugal inicia-se como um fluxo de migrantes qualificados profissionais da área de marketing, dentistas e trabalhadores do setor de informática que migram para trabalhar em Portugal (Feldman-Bianco, 2002, Machado, 2005, Bógus, 2007, Peixoto e Figueiredo, 2007). Segundo os autores, a primeira fase da migração brasileira, geralmente apontada entre as décadas 1980 e 1990, foi caracterizada principalmente pela movimentação de indivíduos com qualificação.

Ao longo dos anos 90 há uma intensificação desse movimento e uma diversificação do perfil desse grupo migrante. Esta é considerada a segunda fase migratória, que se caracteriza pela inserção de indivíduos menos qualificados e com condições laborais mais precárias inserindo-se no setor de serviços e na construção civil. Esta segunda leva de brasileiros, de acordo com os autores, é quantitativamente superior, em termos absolutos, à primeira leva.

Nesse movimento há também um aumento expressivo do número de mulheres que migram sozinhas ou fazem parte de uma estratégia familiar, embora também ocorram os processos de mulheres que migram com maridos ou os pais (Padilla, 2012, Frangella, 2014, Assis, 2015). Estas que se inserem no setor de serviços domésticos como babas ou faxineiras, na área de estética como manicures, cabeleireiras ou depiladoras, como cuidadoras de idosos e no mercado do sexo. Por fim, cabe destacar que as mulheres brasileiras vivenciam um processo de exotização e sexualização que, se por um lado cria 
oportunidades no mercado de trabalho, por outro gera discriminação e preconceito ao associarem a imagem de mulher brasileira com a prostituição ${ }^{5}$. Há uma representação sobre a mulher brasileira que produz uma associação entre gênero e nacionalidade ocorrendo uma sexualização da mulher brasileira que relaciona "características"(sensualidade, alegria, simpatia) com a inserção no mercado do sexo, o que gera discriminação em relação às imigrantes brasileiras em Portugal e em outros países europeus.

A intensificação do fluxo na virada dos anos 1990 para o início dos anos 2000 representou também uma modificação do perfil de classe, raça e gênero. A migração expressiva de brasileiros para Portugal conhecida como segunda vaga de migrantes apresenta um perfil de classes médias e medias baixa e de escolarização mais baixa (Machado, 2007, Padilla, 2012).

Com relação à documentação, esse fluxo se caracterizava no final da década de 1990, como um movimento de trabalhadores indocumentados, essa situação se modificou no inicio do ano $2000 \mathrm{com}$ o "acordo Lula". Assinado a 11 de Julho de 2003, o acordo - conhecido nos meios brasileiros em Portugal como "acordo Lula" - previa a legalização de todos os brasileiros que entraram em Portugal até à data da assinatura do protocolo e que tinham um contrato de trabalho válido 6 . $\mathrm{O}$ acordo Lula diminuiu de maneira significativa a incidência de imigrantes indocumentados em Portugal e torna esse país uma porta de entrada rumo a Europa. No entanto, com a o grande movimento de retorno de brasileiros e também devido ao fato de muitos brasileiros terem permanecido desempregados, muitos brasileiros perderam a essa permanência que lhes permitia ficar regular

\footnotetext{
5 Ver (Luciana Pontes, 2004, Beatriz Padilla ( 2007, 2014) Kachia Techio (2006), Fernandes (2008), Assis (2015).

6 Segundo Beatriz Padilla (2007), o acordo Lula foi assinado juntamente como outros dois acordo bilaterais e provavelmente o mais famoso e de grande impacto para os brasileiros. Para a autora a inovação nesse acordo é que foi um processo de regularização extraordinária para um grupo especifico de imigrantes. Embora o processo tenha contribuído para a legalização de milhares de brasileiros, muitos que se registraram no período não conseguiram comprovar todos os documentos solicitados e não foram regularizados.
} 
em Portugal, tornando-se novamente indocumentados.

Até meados da primeira década dos anos 2000, os brasileiros que se tornaram o grupo mais representativo em Portugal. Estes foram atraídos por uma legislação que possibilitava regularização, pelas redes migratórias informais e também por um mercado de trabalho aquecido que absorvia esses fluxos da década. Com a crise econômica de 2009, observou-se uma queda e diminuição de imigração, segundo dados do Serviço de Estrangeiros - SEF, o que pode observado pelo movimento de retorno de imigrantes brasileiros (Padilla, 2012, Peixoto, 2011). Segundo dados do SEF, ocorreu uma diminuição da população estrangeira residente em Portugal. A despeito dessa redução, os brasileiros continuam sendo a principal comunidade estrangeira em Portugal, com 82.590 cidadãos. O retorno de emigrantes ao Brasil ocorreu num contexto em que o Brasil aparecia no cenário econômico internacional como um país em crescimento econômico, no qual a crise econômica mundial, ainda não fazia surtir seus efeitos. Nesse período (2008-2014) muitos retornaram ao Brasil, pois até 2014 o pais vivia um boom econômico, e a crise econômica mundial ainda não havia chegado ao país ou emigraram para outros países europeus como a Inglaterra.

\section{O retorno ao Brasil, a crise e a reemigrarão a Europa}

No entanto, o cenário brasileiro se modificou drasticamente de 2014 para 2017, o país saiu de uma situação de pleno emprego para cerca de 12 milhões de desempregados, além de uma grave crise política que levou a impeachment de sua presidente eleita.

Nesse cenário, muitos migrantes que haviam retornado ao Brasil, vivenciam além da crise econômica e política no Brasil, as dificuldades vivenciadas no retorno ao pais, pois não se volta para o mesmo lugar nem para as mesmas relações sociais, e nesse cenários muitos brasileiros e brasileiras reemigraram para a Europa. 
Assim relata Janaina7, que vive há 13 anos em Lisboa e que o marido retornou ao Brasil em 2014:

Um cunhado prometeu sociedade num restaurante no Brasil para meu marido e eu. Eu trabalho aqui em restaurante desde que cheguei e sonhava em ter meu restaurante, queria levar o que aprendi aqui para lá. Ele foi na frente e eu fiquei, para vender tudo e esperar para ir com as crianças. Mas depois de alguns meses, vimos que não era o que haviam prometido e o Brasil não havia melhorado, não teria lá a vida que tenho aqui, falei com ele para voltar, eu não cheguei a ir e fizemos tudo de novo. Meu irmão também foi, ficou dois anos e agora retornou, também não deu certo lá.

É nesse contexto elucidado por Padilla (2012), Siqueira (2009) e Fernandes e Castro(2013), que este artigo se propõe a analisar as trajetórias configurações das relações familiares, afetivas e de gênero na migração dos brasileiros e brasileiras rumo na Europa, tendo como um dos principais destinos Portugal.

Para além de compreender essa circularidade migratória, na qual se inserem mulheres e homens os brasileiros, esse artigo apresenta dados preliminares do projeto de pesquisa que está em desenvolvimento em Lisboa, Portugal que busca compreender como a reconfiguração de laços afetivos e familiares no processo de ir e vir entre o Brasil e a Europa, tendo como um dos principais destinos, Portugal.

\section{Gênero e Afetos entre o Brasil e Europa: a mudança nas expectativas migratórias}

Em 2014 e 2015 estive em Portugal, em Lisboa, e na Itália na região do Vêneto, para compreender o direcionamento do fluxo rumo a Europa e intensificação da presença brasileira em Portugal, que se

\footnotetext{
7 Janaina, nome fictício, emigrou em 2001, com 19 anos, para Lisboa em busca de oportunidades e também para fugir de um relacionamento no Brasil. O namorado veio atrás, se tornou marido e já tem 2 filhas.
} 
converteu no grande pais de destino de migrantes brasileiros, enquanto a Itália continuava a receber migrantes, muitos deles descendentes dos imigrantes que chegaram ao Brasil o século XIX. Assim os brasileiros $\backslash$ as se espraiavam pela Europa. Tratava-se de uma pesquisa exploratória de natureza etnográfica para pensar o projeto de pós-doutorado. Nesse período realizei cerca de 20 entrevistas com emigrantes de diferentes origens regionais, provenientes de camadas medias e também de classes medias baixa e com baixo nível de escolaridade, que permaneciam na Europa a despeito da crise econômica na Europa, que se intensificará a partir de 2009. No que se refere a migração para a Itália o foco foi nos descendentes de imigrantes italianos, tanto migrantes quanto estudantes. Em Portugal, as mulheres representavam em 2003, 45\% dos imigrantes brasileiros segundo o SEF. As ocupações predominantes das mulheres imigrantes brasileiras são nas áreas do comércio, serviços e restauração e a tendência é serem empregadas em trabalhos sem qualificação. Nesses trabalhos, com destaque para o ramo de estética e beleza, manicures, depiladoras, cabelereira se utilizam dos mesmo imaginário que muitas vezes é relacionado a preconceito e discriminação para conseguir nicho no mercado de trabalho - a simpatia étnica (Padilla 2007, Machado, 2007, Fernandes, 2009).

Nos seus depoimentos era muito recorrente a fala de Portugal como um lugar de oportunidades, a despeito da crise, e mesmo num cenário econômico mais favorável no Brasil, preferiam ficar na Europa tinham "medo de voltar" e destacam a sensação de liberdade e segurança que sentiam em Portugal, embora enfrentassem dificuldades e de algumas situações de preconceito.

Lembro-me da fala de Eliete $^{8}$ migrante que estava desempregada há dois anos, vivendo de trabalhos eventuais, mas preferia ficar em Portugal a voltar para o Brasil .

\footnotetext{
8 Eliete tinha na época 34 anos, tinha vindo para Lisboa no inicio dos anos 2005 e estava aqui há 5 anos. Era solteira, frequentava a Igreja evangélica. No momento da entrevista estava sem emprego, mas não pensava em retornar ao Brasil. Entrevista concedida em julho de 2014
} 
Lá em eu não tenho perspectiva, não estudei aqui, não tenho profissão para exercer lá e aqui, tenho mais oportunidades. Estou desempregada no momento, mas com o que juntei trabalhando consigo me manter e tenho uma reserva, aqui me sinto mais segura, não tenho coragem de voltar agora (Eliete, entrevista, julho de 2014).

Nesse contexto o que começou a me intrigar é: como construíam os projetos migratórios? Muitas vinham sozinhas e deixavam os filhos/as no Brasil, para buscar num segundo momento, ou construíam suas vidas afetivas aqui se casando com europeus.

Estou falando muito brevemente de mulheres jovens que migraram acompanhando suas mães e de mulheres com mais de 40 anos que migraram com seus maridos ou recém separadas que deixaram seus filhos. São esses e outros arranjos que gostaria de compreender nessa pesquisa em andamento.

Gênero e afetos se cruzam nas trajetórias dessas mulheres, a história de Ana9 é uma das que nos ajudam a pensar sobre como as mulheres brasileiras negociam as identidades de gênero no processo de migração. Ana tinha 41 anos, em 2014 e conheceu Carlos, em 1999, quando trabalhava numa empresa metalúrgica, numa cidade no interior de Minas Gerais, no Brasil.

Quando perguntada como veio para a Itália, assim respondeu: "Foi amor, foi por amor". Em 1998 ela conheceu Carlos no seu trabalho no Brasil, ele não falava português e ela não falava italiano. Eles começaram a namorar, ele retornou para a Itália no início de 1999, depois ele voltou ao Brasil antes do prazo combinado, que seria no final do ano, pois, conforme seu relato "não aguentou de saudades". Viajou para a Itália, em 1999, e não retornou ao Brasil. Casou-se primeiro na Itália, para regularizar sua situação, depois retornou e casou-se no Brasil. Conforme a narrativa de Ana:

\footnotetext{
${ }_{9}$ A história de Ana está relatada no artigo de Zanini, Assis e Beneduzi (2015), retomo aqui pois trata-se de um exemplo de casamento por amor. A entrevista foi realizada em 2014 por Gláucia de O. Assis e Maria Catarina e os nomes são fictícios para garantir a não identificação da entrevistada.
} 
É, outubro a gente casou e... aí aqui nos casamos no civil e no Brasil, em janeiro, nós fizemos o religioso. No Brasil em janeiro... porque meu pai e ele... para ele era importante né, aí nós fizemos no Brasil o religioso (Ana, 2014).

Ana relata que se adaptou rapidamente à nova vida, pois foi muito bem acolhida pela família do marido. Em sua narrativa, não aparecem tensões ou discriminação pelo fato de ser brasileira. Muito pelo contrário, diz que o fato de ser muito alegre e comunicativa a aproxima dos vizinhos da pequena cidade onde mora. Passou por dificuldades, pois morou um tempo na casa dos sogros antes de construir junto com o marido em sua casa própria. Tem dois filhos que falam português e leem também e ela aprendeu o italiano, cuida dos filhos e da casa e não trabalha.

A narrativa de Ana é interessante, pois no Brasil, era uma mulher que tinha seus próprios rendimentos, trabalhava e estudava. Quando migrou, deixou o trabalho e a profissão, não concluiu o curso superior e hoje em dia não trabalha fora, pois considera que o que ganharia trabalhando fora não seria suficiente para pagar alguém para cuidar dos filhos. Sua narrativa é interessante, pois enquanto uma parcela dos relatos aponta para processos de autonomização com o processo migratório, para Ana significou um processo de maior dependência, embora isso não transpareça em seu relato, pois é sócia do marido em sua firma e tudo é decidido junto com ela conforme seu relato. Ana não trabalha fora, cuida da família, marido e filhos, tem pouca inserção no espaço público, participa de atividades na escola dos filhos e encontra as amigas. Portanto, sua vida cotidiana está muito centrada no mundo doméstico/privado. Ana está casada há 15 anos e na sua narrativa se considera feliz com a imagem de boa esposa e mãe construída na relação com o marido e os filhos. Ao mesmo tempo, para atenuar essa autoimagem restrita ao âmbito doméstico, faz questão de dizer que tem uma faxineira para ajudá-la no serviço da casa e que, quando o marido tem que decidir sobre as coisas para comprar, as decisões do casal são compartilhadas. Para ajudar a "matar as saudades" que sentia do Brasil e da família acabou trazendo a prima e ajudando-a a arrumar 
um namorado italiano também. A prima Giulia, também se casou com um amigos em comum dos dois e acabou, igualmente, migrando para a Itália numa rede migratória constituída a partir de afetos.

Ana e Giulia utilizaram dos atributos de mulher brasileira para construírem suas relações afetivas, mas pagam as marcas da sensualidade. Assim como algumas mulheres que entrevistei nos Estados Unidos em 2001, às imagens de sensualidade agregam-se as representações de mulher carinhosa, de boa esposa e mãe, o que confere uma certa vantagem às mulheres no mercado matrimonial.

Em comparação aos homens brasileiros, que muitas vezes que não são representados como bons parceiros, pois são vistos como machistas, autoritários, pouco dispostos a dividir tarefas domésticas, representando modelos de masculinidade pouco valorizados no contexto dos países de migração. Do ponto de vista das masculinidades, os homens brasileiros no contexto da migração "perdem" suas posições de masculinidade hegemônica e tem que renegociar as relações de gênero - perdem poder.

Se o casamento pode ser uma forma de inserção de se distanciar dos estereótipos de gênero que discriminam as mulheres brasileiras, para as mulheres solteiras a negociação com esses marcadores implica numa também numa vigilância sobre o corpo, numa disciplina com relação a como se vestir e também em saber se comportar conforme relata Carla, o corpo é alvo de constantes policiamentos, uma vez que há muitas situações, especialmente para as descendentes, em que a "mulher brasileira" aparece como categoria dominante nas interações:

Porque, de repente, a gente que é brasileiro talvez, é... Te dou um exemplo, talvez seja mais fácil: quando tu vais em locais brasileiros, tu vês como os brasileiros se vestem e como os italianos se vestem. No período do inverno... de neve... as brasileiras geralmente vão com a barriga de fora, com uma sandália... com isso que aqui... jamais se vê esse tipo de coisa e é normal que chame a atenção das pessoas... feito a posta, ou não... se uma faz 
justamente pra chamar a atenção ou não, eu não sei... mas é a mesma coisa, é... tu tem que tentar te adequar, mas isso... adequar... de alguma maneira... $\mathrm{Eu}$ não falo nas pessoas muçulmanas, que de repente usam vestidos longos, tudo, porque faz parte de uma cultura dele... vestir dessa maneira, e eu acho que tirar esse tipo de cultura é... é uma coisa inútil... mas eu falo mais de nós, de aprender... a tentar se vestir um pouco mais decentemente porque... a tendência de muitos brasileiros. E eu tenho visto... agora trabalhando em shoppings daqui pra... daqui, é... em Bassano, em Pádova, em Veneza... de pessoas que, que... se vestem... com... microgona, microssaia, não míni... porque é uma coisa... que tu vê de cara, é... eu vejo de cara quem são os brasileiros... na maneira como se vestem, mas não é uma discriminação minha... (Carla, 2012).

Carla é solteira, ítalo-brasileira e no seu relato se reporta as situações de preconceito e discriminação que podem ocorrer com as brasileiras, assim ao destacar a importância de se vestir adequadamente, assim como fizeram Ana e Giulia, demonstra que na Europa, talvez de uma forma mais marcante que nos Estados Unidos, conforme observei num artigo anterior (Assis, 2011) implicaria, nesse caso, em fugir das marcas de sexualização que funcionam como atributos das mulheres brasileiras.

Essa negociação e esse aprendizado sobre como se colocar na relação com os portugueses, evidencia como os marcadores de gênero e sexualidade são renegociados pelas brasileiras. Cristiane, que vive em Lisboa há mais de 15 anos, é casada com um indiano. Quando a entrevistamos nos recebeu no escritório onde trabalhava e falava com um leve sotaque de português de Portugal. Ao se referir ao imaginário sobre as brasileiras disse

Eu acho que, por exemplo, eu, mulher, eu me senti no inicio assim um pouco... como... eu preciso policiar as minhas atitudes aqui. Por quê? No Brasil, lá na minha região, todo mundo já tá acostumado com o afeto, chega e abraça mesmo, o carinho, isso é muito comum, entendeu? Aqui não. Aqui eles te 
estendem a mão pra te cumprimentar quando cê (você) já tá armada pra ir dar um abraço, por exemplo, assim, entendeu? Então, esse histórico da mulher brasileira aqui em Portugal, né, daquela época que algumas mulheres vieram para se prostituir ${ }^{10}$, e eu acho que isso é algo assim, não é muitíssimo marcado no imaginário do homem, do português. Mas ainda tem um resquiciozinho disso, entendeu? E assim, nosso jeito espontâneo, eu sou uma pessoa muito espontânea. Eu sou assim. (Cristina, 28 anos, advogada)

Marina tem 36 anos e mora há 6 anos em Lisboa chegou aqui para viver com a irmã, mas logo conheceu seu primeiro marido, um português com quem se casou e teve uma vida confortável.

Tinha de tudo, não casei por amor, mas aprendi a gostar dele, pois me respeitava e dava tudo, foi cômodo, ficamos juntos três anos [...] Perdi tudo isso quando me apaixonei por outro português, 10 anos mais jovem [...] então aprendi a dividir tudo, passei a saber quanto custa as coisas, quanto custa pagar a renda e percebi que era capaz de me sustentar e as minhas filhas, é difícil...

A história de Marina apresenta uma narrativa distinta das anteriores. Nesse caso, o casamento significou uma vida mais estável e segura, ela afirma que gostava do marido, mas não o amava e quando conhece um rapaz mais jovem abandona tudo para ficar com um português mais jovem. É no segundo casamento com um homem mais jovem e com quem tem que dividir o aluguel e as contas que se percebe capaz de gerir a própria vida, embora reconheça que é difícil. $\mathrm{O}$ fato das brasileiras se casaram com estrangeiros nesse contexto, é utilizado por outros migrantes como uma categoria acusatória, são acusada de casamento por interesse, tem que enfrentar desconfiança dos familiares e a suspeita de se casam para se legalizar. O que busco demonstrar é que as mulheres constroem relacionamentos em que afetos e interesses se cruzam em busca de uma vida mais estável e de

10 Cristiane e outras mulheres que entrevistei se referiram várias vezes a imagem criadas por outras brasileiras, no que ficou conhecido como Mães de Bragança (Ver Luciane Pontes, 2004) 
relacionamentos mais respeitosos.

Por fim, e sem esgotar as experiências das mulheres migrantes, pois trata-se de uma pesquisa qualitativa e pretendo continuar essa pesquisa para caracterizar melhor essas mulheres, seus relacionamentos afetivos e familiares e como foram construindo seus projetos de permanência na Europa, apesar da crise, compreender as tensões entre processos de agencia e subjugação/exploração e suas estratégias de inserção na sociedade de imigração e, nesse cenário, compreender melhor as mulheres que se casam com homens mais velhos, em casamentos que não tem as marcas do amor romântico, mas da busca pro segurança e respeito Faço um corte e me reporto a minha chegada no inverno de 2017 a Portugal. O Brasil

vive uma situação de grave econômica e política e, antes de encontrar as pessoas que entrevistei quando aqui estive, tenho encontrado muitos migrantes recém chegados, que migrarem com toda a família, só que diferentemente dos migrantes que encontrei em outros momentos são migrantes qualificados que migraram para se inserir no mercado de trabalho como publicitários, profissionais da informática, que trazem as mulheres e filhos para viver em Portugal, num projeto de viver aqui, diferentemente dos que entrevistei em 2014-15, é de permanência em Portugal. Nesse momento o projeto migratório coloca como perspectiva a migração familiar, com projeto de se estabelecer e viver na Europa, os maridos profissionais qualificados e as espeosas também trabalhavam quando viviam no Brasil. O projeto migratório se desenha, quando como profissionais de classe média, não conseguem ver no Brasil as perspectivas de manter o mesmo padrão de vida e resolvem migrar. A migração nesse caso envolve, vender a casa, ou alugar, vendendo tudo o que tinham e vir com 10 malas. Deixar tudo para traz, amigos, bens, carro, escola particular e os confortos da vida de classe média e se inserir numa nvoa realidade em Portugal.

Esses emigrantes recém chegados, muitos deles tem cidadania portuguesa, outros migrarm com vistos de trabalho diferentemente 
dos trabalhadores imigrantes que se regularizam ao longo da sua experiencia migratória já vem com documentação, para els e para os filhos. As mulheres regularizam a documentação quando chegam em Portugal, mas para isso tem que enfrentar um longo percurso no SEF. O que tem me chamado atenção nesse novos migrantes, é o seu relato de mundaça em busca de qualidade de vida, em fugir da violência, em buscar uma outra vida para os filhos, longe da crise econômica e política. Em Portugal, a perdem o status de camadas medias, colocam os filhos em escolas públicas, e se utilizam os serviços públicos de sáude, sentindo-se mutias vezes, mais cidadãos que no Brasil. O que pretendo analisar com mais cuidado a partir de suas falas e da observação do cotidiano são como esses projetos vão se redefinindo e de deparam com as dificuldades cotidianas de se descobrir imigrante na Europa . Nesse contexto as discussões de transnacionalização das relações afetivas e dos seus cruzamentos com classe, gênero e raça irão permear as minhas reflexões.

\section{Referencias}

ASSIS, Gláucia de O. De Criciúma para o mundo os novos fluxos da população brasileira: gênero e rearranjos familiares. In: MARTES, Ana Cristina B.; FLEISCHER, Soraya (Org.). Fronteiras Cruzadas: etnicidade, gênero e redes sociais. São Paulo, Paz e Terra, 2003. p. 199-230.

ASSIS, Gláucia O. Estar aqui... Estar lá: uma cartografia da emigração valadarense para os Estados Unidos. In: REIS, R. R.; SALES, T. Cenas do Brasil Migrante. São Paulo; Boitempo, 1999.

CAMPOS, Emerson. Territórios deslizantes: miscelâneas e exibições na cidade contemporânea Criciúma (1980-2002). Tese (Doutorado em História) - Universidade Federal de Santa Catarina, Florianópolis, 2003.

CAVALCANTI, Leonardo. "Imigrantes", “Imigrados”,,"Estrangeiros”... e a fabricação do "Outro" Imaginário: a Presença Brasileira no Contexto da Imigração na Espanha-10.5102/uri. V 3i2. 282. Universitas: Relações Internacionais, 2007, 3.2.

FERNANDES, Duval Magalhaes; NUNAN, Carolina. O imigrante brasileiro na Espanha: perfil e situação de vida em Madrid. XVI 
Encontro Nacional de Estudos Populacionais.2008.

FERNANDES, Gleiciani Maria de Oliveira. Viver Além-Mar: Estrutura e Experiência de Brasileiras Imigrantes na Região Metropolitana de Lisboa. Dissertação (Mestrado em Antropologia) - Instituto de Ciências Sociais da Universidade de Lisboa, Lisboa, 2008.

FRANGELLA, Simone. O tênue equilíbrio no movimento: a vicinalidade na migração transnacional. Revista de Antropologia, 57, p. 73-106, 2014.

GLICK SCHILLER, Nina. Trasmigrants and Nation-States. Something Old and Something New in the U.S. Immigrant experience. In: HIRSCHMAN, C, KASINITZ, P. and DEWIND, J. (Ed.). The Handbook of international migration: the American experience. New York, Russell Sage Foundation. 1999. p 94-119.

MACHADO, José Igor. Imigração em Portugal. Revista Estudos Avançados, São Paulo, 20, 57, p. 119-135, 2006.

MALHEIROS, Jorge. Os brasileiros em Portugal: a síntese do que sabemos. In: MALHEIROS, J. M (Org.). Imigração brasileira em Portugal, Lisboa: Alto Comissariado para a Imigração e Diálogo Intercultural (ACIDI), 2007.p. 11-39.

MARGOLIS, Maxine L. Goodbye, Brazil: emigrés from the land of soccer and samba. University of Wisconsin Pres, 2013.

MARGOLIS, Maxine L. Little Brazil: an ethnography of brazilian immigrants in New York City. Princeton University Press, 1994.

MARTES, Ana Cristina B. Brasileiros nos Estados Unidos: um estudo sobre imigrantes em Massachusetts. São Paulo: Paz e Terra, 2000.

MARTINE, George. A globalização inacabada: migrações internacionais e pobreza no século 21. São Paulo Perspec., São Paulo, v. 19, n. 3, p. 3-22, set. 2005 .

MASANET, Erika.; PADILLA, B. La inmigración brasileña en Portugal y España ¿Sistema migratorio Ibérico? OBETS: Revista de Ciencias Sociales, Alicante: Universidad de Alicante, v.5, n.1, p.49-86, 2010.

NUNAN, Carolina; PEIXOTO, João. Crise econômica e retorno dos imigrantes brasileiros em Portugal. Revista Interdisciplinar da Mobilidade Humana, 20.38, 2012.

OLIVEIRA, Antônio Tadeu. Um panorama da migração internacional a partir do Censo Demográfico de 2010. Revista Interdisciplinar da Mobilidade Humana, 21.40, 2013.

PADILLA, Beatriz. A imigrante brasileira em Portugal: considerando o gênero na análise. In: MALHEIROS, J. M (Org.). Imigração brasileira em Portugal. Lisboa: Alto Comissariado para a Imigração e Diálogo 
Intercultural (ACIDI), 2007.p. 113-135.

PADILLA, Beatriz. Acordos bilaterais e Legalização: O impacto na integração dos imigrantes brasileiros em Portugal. In: MALHEIROS, J. M (Org.). Imigração brasileira em Portugal. Lisboa: Alto Comissariado para a Imigração e Diálogo Intercultural (ACIDI), 2007. p. 217-226.

PADILLA, Beatriz; ORTIZ, Alejandra. Fluxos migratórios em Portugal: do boom migratório à desaceleração no contexto de crise. Balanço e desafios. REMHU - Rev. Interdiscip. Mobil. Hum, v. 20, n. 39, p. 159184, 2012.

PEIXOTO, João; FIGUEIREDO, Alexandra. Imigrantes brasileiros e mercado de trabalho em Portugal. Imigração Brasileira em Portugal. Lisboa, ACIME/Observatório da Imigração, 2007. p. 87-111.

PONTES, Luciana As Mulheres Brasileiras na Mídia Portuguesa. Cadernos Pagu, n. 23, p.229-256, jul./ dez. 2004.

ROSALEN, Eloisa. Das muitas memórias dos exílios: uma leitura analítica dos livros Memórias do Exílio e Memórias das Mulheres do Exílio. XVIII SNHistoria. Disponível em: http://www.snh2015.anpuh.org/resources/anais/39/1438608862_ ARQUIVO_AnpuhNacional EloisaRosalen.pdf.

SALES, Teresa. Identidade étnica entre imigrantes brasileiros na região de Boston. In: REIS, Rossana R.; SALES, Teresa (Org.). Cenas do Brasil migrante. São Paulo: Boitempo, 1999a. p. 17-44.

SALES, Teresa. Brasileiros longe de casa. São Paulo: Cortez , 1999b.

SAVOLDI, Adiles et al. O caminho inverso: a trajetória de descendentes de imigrantes italianos em busca da dupla cidadania. Dissertação (Mestrado em Antropologia) - Programa de Pos-graduação em Antropologia Social, 1998.

SIQUEIRA, Sueli, ASSIS, G. O., CAMPOS, Emerson César. Of the place for the global: configuration of transnational bows between Brasil and the United States In: LATIN AMERICAN STUDIES ASSOCIATION, 2010, Toronto.

SIQUEIRA, Sueli. Sonhos, sucesso e frustrações na emigração de retorno. Brasil/Estados Unidos. Belo Horizonte: Argvmentvm, 2009. 188 p

ZANINI, Maria Catarina C.; ASSIS, Gláucia de Oliveira; BENEDUZI, Luis Fernando. Ítalo- Brasileiros na Itália no século XXI: retorno à terra dos antepassados, impasses e expectativas. REMHU: Revista Interdisciplinar da Mobilidade Humana, 21.41, p. 139- 162, 2013. 